\title{
The corrosion of stirrups and its effect on the seismic fragility of a corroded reinforced concrete (RC) column
}

\author{
Guanghui Zhang \& Bing Li \\ School of Civil and Environmental Engineering, \\ Nanyang Technological University, Singapore
}

\begin{abstract}
As service rates increase, the corroded rebar stands out as a major problem for existing reinforced concrete $(\mathrm{RC})$ columns in a corrosion-inducing environment. The corrosion of stirrups is more serious than that of longitudinal bars, due to smaller clear concrete cover and smaller diameter. It deteriorates the confinement behaviour and thus decreases the shear resistant capacity, potentially changing the failure modes from ductile flexural failure mode to brittle flexural-shear failure mode, or even shear failure mode. Therefore, the evolution of the seismic damage pattern of existing corroded RC columns and its service-year related fragility analysis are becoming heated research topics in the field of structure hazard prevention research. The objectives of this paper will be to focus on how to use FEM software to numerically simulate the seismic behaviour of corroded columns accounting for materials deterioration and bond degradation. Pushover curves shown that a transverse rebar corrosion level above $10 \%$ could reduce the seismic capacity of columns by a great extent. In addition, the stiffness, ductility and energy dissipation capacity declines. It also demonstrated the transition of failure mode from flexure failure to shear failure as the corrosion level of stirrups increased. The fragility analysis based on the FEM results indicated that the $\mathrm{RC}$ column with corroded stirrups is much more vulnerable.
\end{abstract}

Keywords: stirrup corrosion, bond degradation, seismic fragility analysis, FEM, damage pattern, brittle failure. 


\section{Introduction}

The corrosion of reinforcement steel bars (rebar) is a natural electrochemical reaction $\mathrm{RC}$ structures have to face with. It is exacerbated by exposure to corrosion-inducing environment factors, including de-icing salt, marine salty water, carbon dioxide, sulfur dioxide, etc. The chloride from salt $(\mathrm{NaCl})$ could make hazardously chemical attack on steel bar by acting as an efficient catalyst in the corrosion process. The corrosion of steel bar in the existing reinforced concrete structure has raised great concern over its safety and seismic performance among practising engineers, researchers and residents, etc., because steel bar is the most essential element in RC. Corrosion reduces the effective cross-section area of longitudinal and transverse rebars. As shown in Figure 1, the volume expansion of the corrosion product will give rise to cover cracking, as a result of which effective concrete area could be reduced.
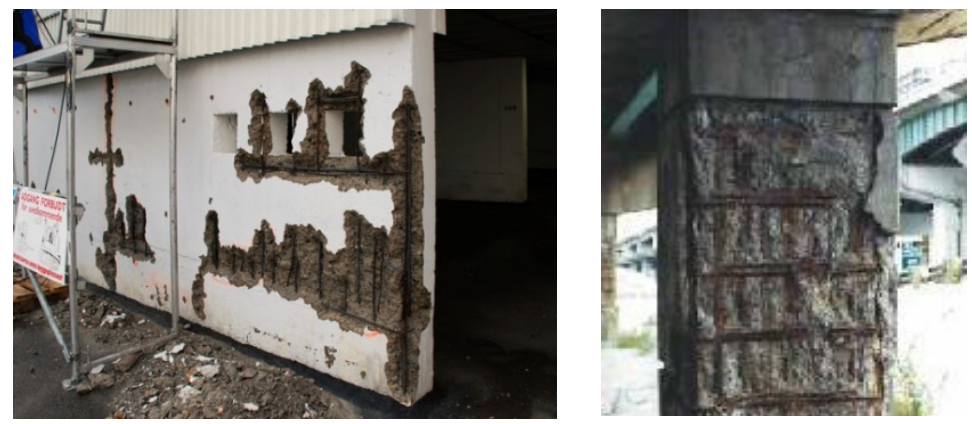

Figure 1: Corrosion of transverse rebars.

Furthermore, the interaction between concrete and steel bar could be changed fundamentally as the steel bars have increasingly corrosion level. In the primary phase, the expansion of the corrosion products enhances the confinement behaviour of the concrete to the rebar. The particle of corrosion products raises the friction coefficient, which is more obvious for smooth bars. The two factors both contribute to the increase of bond strength in the primary phase. But as more corrosion products accumulate, the chemical cohesion will be deteriorated. It may even lead to the reduction of the friction coefficient. For deformed bar, the ribs could be eradicated, which deduces the mechanical interlocking. And the expansion effect of the corrosion products can lead to the cracking of the concrete cover, conversely resulting in the decrease of the confinement. Thus the bond strength declines as the corrosion level exceeds the boundary value (generally it is 5\%).

In the primary phase, the expansion of the corrosion products enhances the confinement behaviour of the concrete to the rebar. Moreover, the particle of corrosion products raises the friction coefficient, which is more obvious for smooth bars. The two described factors both contribute to the increase of bond strength in the primary phase. But as more corrosion products accumulate, the 
chemical cohesion will be deteriorated. It may even lead to the reduction of the friction coefficient. For deformed bar, the ribs could be eradicated, which deduces the mechanical interlocking. And the expansion effect of the corrosion products can lead to the cracking of the concrete cover, conversely resulting in the decrease of the confinement. Thus the bond strength declines as the corrosion level exceeds the boundary value (generally it is $5 \%$ ).

In the corroded RC experimental study and engineering investigation, many scholars including Li and Yang [1], Ma et al. [2] and Wang and Liang [3] found that the transverse rebar could undergo more severe damage than longitudinal rebar, and even break at the junction point with the longitudinal rebar. Because the comparative smaller depth of concrete cover for transverse rebars makes transverse rebars more easily reached by chloride and other corrosion induction chemicals. Besides, the diameter transverse rebars are smaller than that of the longitudinal reinforcement so transverse reinforcement is more vulnerable to corrosion, especially those at the corner of the column. So, transverse rebar corrosion turns out to start earlier and have higher levels than longitudinal rebar.

The corrosion of transverse rebars will seriously degrade the confinement behaviour and thus reduce the shear resistance of the column. Consequently the damage mode could be shifted from ductile bending failure to brittle bendingshear failure or shear failure. However, up until now experimental study and numerical modelling has been focused on how corroded longitudinal rebars affect the seismic performance and fragility of RC beam in general and the corrosion level of transverse rebars had been underestimated. Uncertainties remain on how severely corroded transverse rebars will affect the mechanical strength, seismic capacity and seismic fragility of RC element column.

Therefore, this paper will firstly talk about using NLFEA software Abaqus to simulate corroded RC structure, especially on how to model corrosion-induced cracked concrete, corroded steel rebar, and the bond strength between concrete and rebar, etc. Then based on these techniques, this paper will present parameter study on how highly corroded transverse rebar affects seismic behaviour of RC circular column, and fragility curves using nonlinear pushover analysis.

\section{Modelling methodology of corroded RC}

The high nonlinearity of corroded RC structures can be attributed to cover concrete with corrosion-induced cracks, deteriorated steel bar, and degraded bond strength between concrete and rebar. Ou et al. [4], Sæther and Sand [5] and many other researchers had looked at how to numerically simulate corroded RC with different finite element analysis software and different approaches. This research utilizes popularized Nonlinear Finite Element Modelling software Abaqus version 6.10.1. It has enjoyed great fame for handling highly plastic problems and smart solver with automatic increment [6]. This section will explain the challenges in modelling corroded $\mathrm{RC}$ and the methods used to crack them with Abaqus. 


\subsection{Cover concrete with corrosion-induced cracking}

Bazant [7], Liu and Weyers [8], and Vu et al. [9] had conducted analytical and numerical research on how to model corrosion-induced cracking. These approaches are mostly based on the closed-from assumption. In this assumption, corrosion products replace the concrete-steel interface. The expansion of corrosion products result in the evolution of radial stress in the surrounding concrete. The concrete crack occur when the radical stress has exceeds the tensile strength. Different kinds of modification factor were proposed to consider the stiffness degradation of cracked concrete. Ou et al. [4] proposed a softening effect coefficient to consider the softening effect of cracking concrete, as follows:

$$
\zeta=\frac{0.9}{\sqrt{1+600 \varepsilon_{\mathrm{r}}}}
$$

where $\varepsilon_{r}$ is the tensile strain of the cover concrete, the following figure shows the stress strain curve of cracked cover concrete. It could be expressed as the equations 4-5:

$$
\sigma=\left\{\begin{array}{rr}
\zeta \mathrm{f}_{c}^{\prime}\left(2\left(\frac{\varepsilon}{\zeta \varepsilon_{0}}\right)-\left(\frac{\varepsilon}{\zeta \varepsilon_{0}}\right)^{2}\right) & \varepsilon<\zeta \varepsilon_{0} \\
\zeta \mathrm{f}_{c}^{\prime}\left(1-\left(\frac{\frac{\varepsilon}{\zeta \varepsilon_{0}}-1}{\frac{2}{\zeta}-1}\right)^{2}\right) & \varepsilon \geq \zeta \varepsilon_{0}
\end{array}\right.
$$

where $\varepsilon_{0}$ is the concrete strain when concrete reaches the peak stress.

Abaqus has two different material models for concrete: one is damaged plasticity; the other is smeared cracking [6]. Both could describe the stress strain curve by specifying the data points. Damaged plasticity is used in this modelling of cracked concrete, because it is superior to smeared cracking in terms of convergence rate. As has been described above, softened cover concrete caused by corrosion cracking is simulated by introducing softening factors and modified concrete stress strain curve.

\subsection{Geometry and material strength of corroded rebar}

Corrosion initially damaged rebar by eating away steel and reducing the cross section. In the experimental study, corrosion level is generally measured by percentage of decreased bar weight over prime bar weight $[2,10]$. However, this method fails to describe the true corrosion status by ignoring the position, the depth and area of corrosion pit. This rough way of calculating rebar corrosion level could be idealized as uniform cross section reduction. Even though corrosion is localized and non-uniform by nature, this method is proven to represent the geometry change of rebar and yield good modelling results. Lee et al. [11] reported that corroded steel bar has reduced yield strength and maximum strength, smaller elastic modulus. Regression analysis had produced 
linear equations to calculate the mechanical parameters of corroded rebar, as illustrated in Table 1 and Figure 2. Abaqus provides steel material model with plasticity, explicitly identifying the stress and the corresponding inelastic strain.

Table 1: Mechanical properties of corroded reinforcement.

\begin{tabular}{|l|c|}
\hline $\begin{array}{l}\text { Mechanical Properties } \\
\text { Parameters }\end{array}$ & Equation for Mechanical Properties \\
\hline Yield Strength & $\sigma_{\mathrm{cy}}=(1-1.98(\Delta \mathrm{c} / 100)) \sigma_{\mathrm{y}}$ \\
\hline Ultimate Strength & $\sigma_{\mathrm{cu}}=(1-1.57(\Delta \mathrm{c} / 100)) \sigma_{\mathrm{u}}$ \\
\hline Elastic Modulus & $\left.\mathrm{E}_{\mathrm{cs}}=(1-1.15 \Delta \mathrm{c} / 100)\right) \mathrm{E}_{\mathrm{s}}$ \\
\hline Elongation & $\delta_{\mathrm{c}}=(1-2.59(\Delta \mathrm{c} / 100)) \delta$ \\
\hline
\end{tabular}

where $\Delta c$ is the corrosion level $(\%)$. The following shows reduction factor for each of the parameters of corroded rebar.

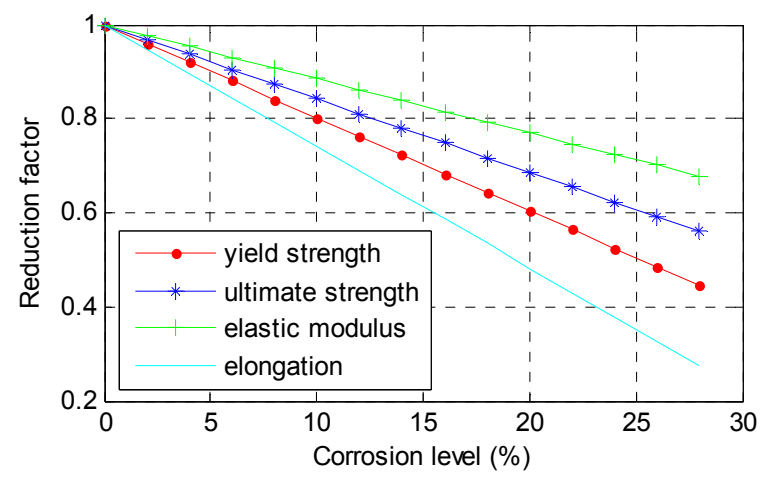

Figure 2: Strength degradation of corroded rebar.

\subsection{Simulate bond strength degradation in Abaqus}

In modelling concrete, generally practice is to model rebars as truss or beam elements and embed them into concrete which is usually discretized as solid element. This approach has been based on the "perfect bond" assumption that concrete is "perfectly" connected to concrete, which would overestimate the capacity of corroded RC structure.

CEB-FIP 1990 [12] provides guidance on the bond-slip value of confined concrete, as shown in Figure 3 and Table 2; according to which, the bond strength depends on two major conditions - whether the concrete is confined or not and whether the bond is good. In addition the ascend branch of the model is defined by the equation: 


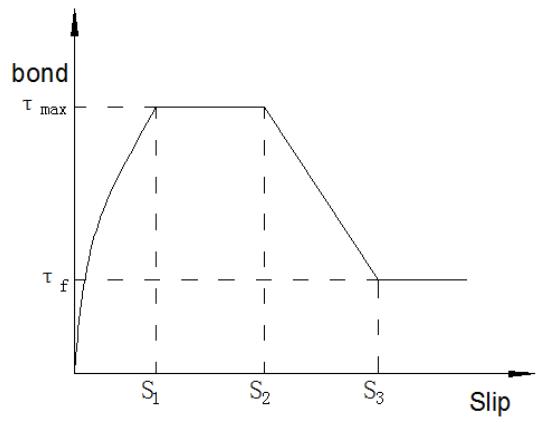

Figure 3: Bond-slip relationship.

Table 2: Parameters for defining bond-slip value.

\begin{tabular}{|l|l|l|l|l|}
\hline & \multicolumn{2}{|l|}{ Unconfined Concrete } & \multicolumn{2}{l|}{ Confined Concrete } \\
\hline & $\begin{array}{c}\text { Good Bond } \\
\text { Condition }\end{array}$ & $\begin{array}{c}\text { All Other } \\
\text { Bond } \\
\text { Condition }\end{array}$ & $\begin{array}{c}\text { Good Bond } \\
\text { Condition }\end{array}$ & $\begin{array}{c}\text { All other } \\
\text { Bond } \\
\text { Condition }\end{array}$ \\
\hline $\mathrm{S}_{1}(\mathrm{~mm})$ & 0.6 & 0.6 & 1 & 0.6 \\
\hline $\mathrm{S}_{2}(\mathrm{~mm})$ & 0.6 & 0.6 & 3 & 0.6 \\
\hline $\mathrm{S}_{3}(\mathrm{~mm})$ & 1.0 & 1.0 & $\begin{array}{l}\text { Clear rib } \\
\text { spacing }\end{array}$ & $\begin{array}{l}\text { Clear rib } \\
\text { spacing }\end{array}$ \\
\hline \multicolumn{1}{|c|}{$\alpha$} & 0.4 & 0.4 & 0.4 & 0.4 \\
\hline$\tau_{\max }(\mathrm{MPa})$ & $2 \sqrt{\mathrm{f}_{\mathrm{c}}^{\prime}}$ & $\sqrt{\mathrm{f}_{\mathrm{c}}^{\prime}}$ & $2.5 \sqrt{\mathrm{f}_{\mathrm{c}}^{\prime}}$ & $1.25 \sqrt{\mathrm{f}_{\mathrm{c}}^{\prime}}$ \\
\hline$\tau_{\mathrm{f}}(\mathrm{MPa})$ & $0.15 \tau_{\max }$ & $0.15 \tau_{\max }$ & $0.4 \tau_{\max }$ & $0.4 \tau_{\max }$ \\
\hline $\mathrm{S}_{4}(\mathrm{~mm})$ & - & - & $0.5 \mathrm{~S}_{3}$ & $0.5 \mathrm{~S}_{3}$ \\
\hline$\tau_{\mathrm{y}}(\mathrm{MPa})$ & - & - & $0.5 \tau_{\mathrm{f}}$ & $0.5 \tau_{\mathrm{f}}$ \\
\hline
\end{tabular}

$\mathrm{Xu}$ [13] tested the bond strength of accelerated carrion specimen on different corrosion levels and conducted regression analysis on the experiment data, and proposed the relationship between the bond strength reduction factor and different corrosion levels, as follows:

$$
\beta= \begin{cases}1+0.5625 \eta-0.3375 \eta^{2}+0.055625 \eta^{3}-0.003 \eta^{4} & \eta \leq 7 \% \\ 2.0786 \eta^{-1.0369} & \eta>7 \%\end{cases}
$$

where $\beta$ is the bond strength reduction factor; $\eta$ is the corrosion level.

Abaqus [6] has the functionality to model the bond behaviour between the concrete and reinforcement by defining interaction contact properties with tangential behaviour, normal behaviour and cohesive behaviour. Tangential behaviour could be defined as penalty friction formulation with friction coefficient, shear stress limit, and elastic slip stiffness, etc., which altogether could fully simulate the bond slip behaviour in corroded RC structure. 


\section{Numerical study on influence of transverse rebars}

\subsection{Details of modelling specimen}

In order to clarify the influence of corroded transverse rebars on the seismic capacity of RC columns, it is essential to look at transverse rebar corrosion level separately. A RC circular column in the experimental study by Ma et al. [2] had been chosen. Circular column has dimension as shown in Figure 4, concrete cylindrical strength is $20.1 \mathrm{MPa}$; clear cover depth is $30 \mathrm{~mm}$; yield strength and ultimate strength of longitudinal rebar is $373 \mathrm{MPa}$ and $572 \mathrm{MPa}$; yield strength of transverse rebar is $327 \mathrm{MPa}$ and $510 \mathrm{MPa}$. As has been discussed, researching on how transverse rebar corrosion affects the seismic capacity holds value in understanding corrosion more thoroughly. In order to achieve this goal, a parameter study has been design with transverse rebar corrosion level, longitudinal rebar corrosion level as the control variables, shown in Table 3. A set of sixteen samples had been created, denoted as LxTy, in which x means corrosion level of longitudinal bar and y means corrosion level of transverse bar.
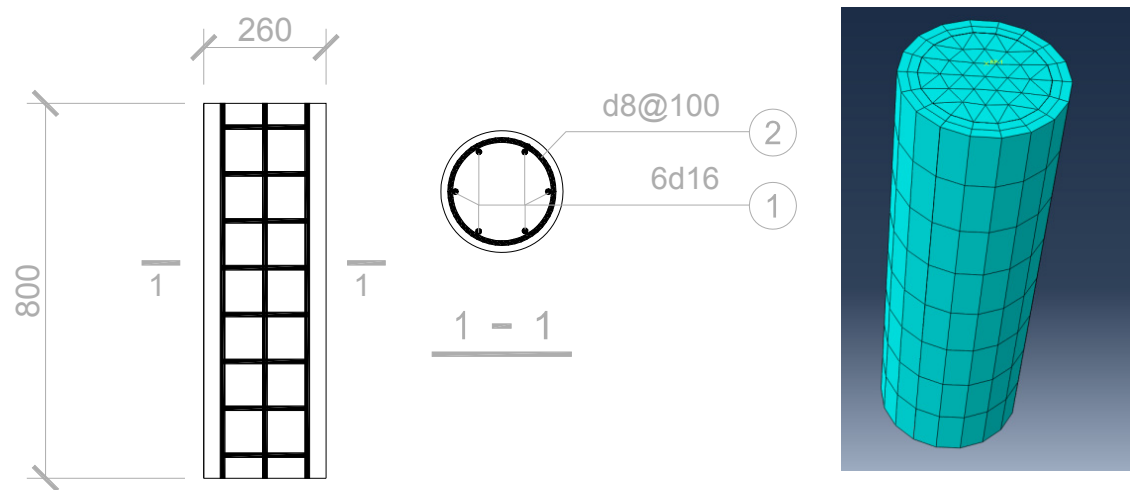

Figure 4: Dimension of RC circular column and rebar detailing and FEM model (unit: $\mathrm{mm}$ ).

Table 3: Control variables for parameter study.

\begin{tabular}{|c|c|c|c|c|}
\hline$\Delta c_{l}$ & \multicolumn{4}{|c|}{$\Delta c_{t}$} \\
\hline $0 \%$ & $0 \%$ & $5 \%$ & $10 \%$ & $15 \%$ \\
\hline $5 \%$ & $5 \%$ & $10 \%$ & $15 \%$ & $20 \%$ \\
\hline $10 \%$ & $10 \%$ & $15 \%$ & $20 \%$ & $25 \%$ \\
\hline $15 \%$ & $15 \%$ & $20 \%$ & $25 \%$ & $30 \%$ \\
\hline
\end{tabular}

According to Table 3, a total of 16 models have been created. As is shown in Figure 6, in the 3D model concrete is discretized as solid homogenous element; rebars are modelled as truss element; the interaction between concrete and steel 
bar is simulated by contact properties. The material property of cracked cover concrete and concrete rebar contact is introduced in the last section; Truss element section area had been reduced according to corrosion level. And each element had been subject to monotonic pushover analysis. Axial load ratio is 0.15 . The maximum displacement at top of column is $50 \mathrm{~mm}$, which makes the drift ratio as $6.25 \%$.

\subsection{Parameter study result}

Reaction force $\mathrm{F}_{r}$ and displacement $\mathrm{D}$ had been fetched from analysis results, as it could represent the overall seismic capacity. Previous analysis has yielded 16 pushover curves, as shown in Figures 5-7. Specimens with the same longitudinal rebar corrosion level almost yield at the same displacement. In Figure 5, as the longitudinal corrosion level increases, the columns have smaller maximum strength at smaller displacement. The seismic capacity and elastic behaviour are still controlled by longitudinal bars. Separate investigation reveals that columns with transverse rebar severely damaged tend to have steeper descending branch and reaction force decreases comparatively faster, which is fully demonstrated by L0T15 and L5T20 in Figure 6. Columns with high transverse corrosion level have more apparently strength loss and ductility loss after the yielding because of the sharp reduction of confinement behaviour. As illustrated in Figure 6, a brittle failure appeared in the specimen L0T5 and L5T15 L5T20 while the longitudinal rebar do not have high corrosion levels. Corrosion of transverse rebar fundamentally changes the failure modes of columns. Figure 7 shows that corrosion level of longitudinal rebars reaches $15 \%$, and the differences in the descending branches had become minor. As the corrosion level of longitudinal

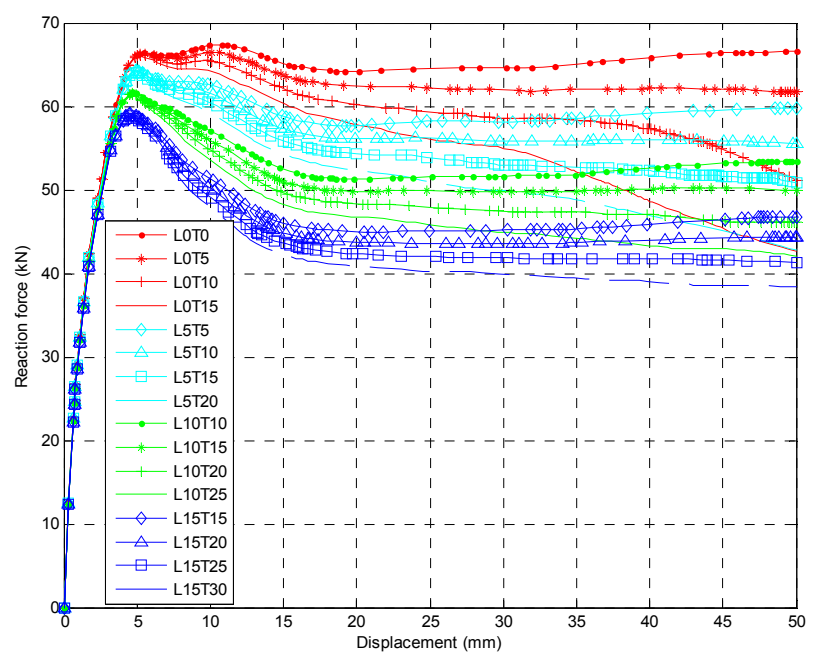

Figure 5: Pushover curves of L0T0-L0T15 and L5T5-L5T20. 
rebars increases, the effect of transverse rebars weakens. As a matter of fact in the natural corrosion phenomena of RC structures, the corrosion level of longitudinal rebars hardly reaches $15 \%$, while transverse rebar has greater probability to suffer from much higher level corrosion.

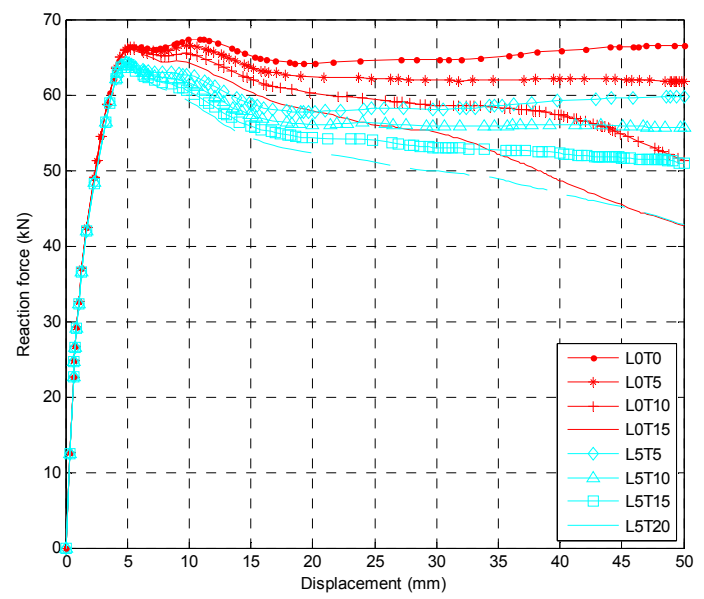

Figure 6: Pushover curves of L0T0-L0T15 and L5T5-L5T20.

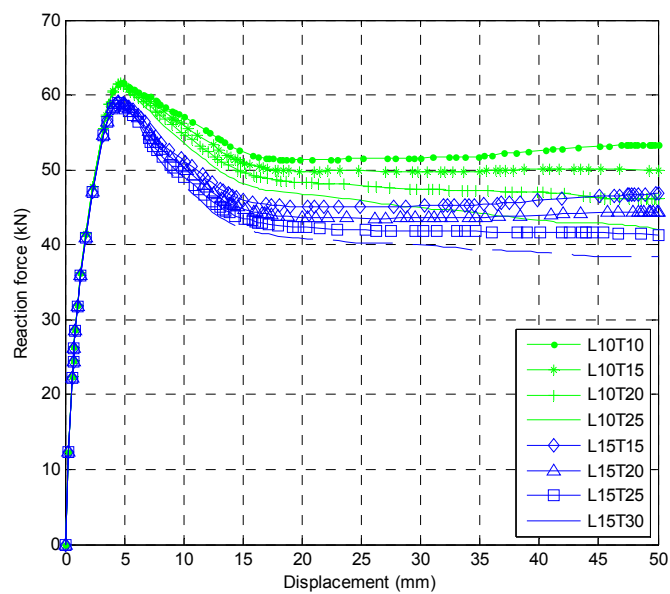

Figure 7: Pushover curves of all specimens.

\subsection{Fragility analysis based on nonlinear pushover analysis}

Fragility function describes probability that seismic demand $D$ exceeds seismic capacity $C$ for designated limit states, as expressed as:

$$
\mathrm{F}_{\mathrm{c}}(\mathrm{d})=\mathrm{P}[\mathrm{D}>C \mid \mathrm{D}=\mathrm{d}]=\Phi\left[\frac{\ln \left(\mathrm{d} / \mathrm{m}_{\mathrm{C}}\right)}{\beta_{\mathrm{C}}}\right]=\Phi\left[\frac{\ln (\mathrm{d})-\alpha_{\mathrm{C}}}{\beta_{\mathrm{C}}}\right]
$$


where $\mathrm{m}_{\mathrm{C}}, \alpha_{\mathrm{C}}$ and $\beta_{\mathrm{C}}$ are the median, logarithmic mean and logarithmic standard deviation (S.D.) of seismic capacity. Freeman et al. [14] put forward the Capacity Spectrum Method (CSM) based on nonlinear static analysis. The capacity spectrum is established by transforming the base-shear displacement pushover curve into acceleration-displacement-response-spectrum (ADRS) format. Then make demand curve based on different structural vibration periods and corresponding influence coefficients. The targeted displacement or displacement of the performance point (PP) is obtained through the comparison between the capacity spectrum and demand spectrum. According to Freeman's research contribution, official standardized fragility derivation procedures had been made. FEMA (Federal Emergency Management Agency) [15] has issued HAZUS 99, an applicable standard methodology which uses nonlinear pushover analysis to establish seismic capacity curve and generate fragility functions. It is a mature and widely employed method in risk estimation of various hazards for diverse infrastructures. HAZUS 99 offers procedures for fragility analysis of corroded RC column in this research. Limit states are categorized into slight damage, moderate damage, extensive damage and collapse according to the drift angle. In order to investigate the fragility of circular columns with severely damaged transverse rebar, we has assumed two cases, L10T10 and L10T20, fragility curves of which are shown in Figure 8. It shows that L10T20 is more vulnerable to extensive damage and collapse than L10T10, meanwhile they have the same probability to have slight and moderate damage. It gives typical examples that $\mathrm{RC}$ structure with more severe damaged transverse rebar is at higher risk of seismic attack.

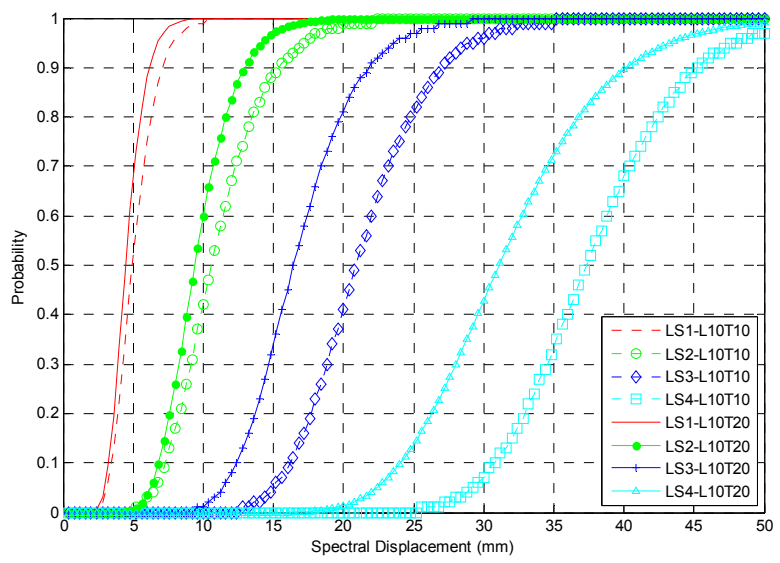

Figure 8: Fragility curves of L10T10 and L10T20.

\section{Concluding remarks}

This paper has suggested applicable methodology of modelling corroded RC structure using software Abaqus 6.10.1. Corrosion induced cover cracking, deteriorated rebar, and the bond strength between concrete and rebar had been 
validly simulated with the functionalities in this software. Simulation results had shown that RC columns with severely corrosion damaged transverse rebar had lower seismic capacity, smaller seismic ductility and brittle failure modes. Transverse rebars have greater influence on the behaviour of columns with longitudinal rebar corrosion level below 15\%. Analysis had demonstrated that high corrosion of transverse rebars shall be considered separately because of its changing power in seismic capacity and ductility. Fragility analysis had found $\mathrm{RC}$ structures with higher transverse corrosion level are more vulnerable. All the columns are tested on monotonic loading so it fails to analyse the energy consuming ability. This paper only presents the analysis results of columns under monotonic loading when transverse rebar has higher corrosion level than longitudinal rebar. Search should be carried out on time-variant the corrosion level of transverse rebar and longitudinal rebar. Probability model shall be made to describe the corrosion level of transverse rebar as a function of longitudinal rebar corrosion level. Furthermore, research work could investigate how to modelling corroded columns under cyclic loading and how to generate fragility curves of corroded RC element.

\section{References}

[1] Li, C. Q. and S. T. Yang, Prediction of concrete crack width under combined reinforcement corrosion and applied load. Journal of Engineering Mechanics, 137(11), pp. 722-731, 2011.

[2] Ma, Y., Che, Y. \& Gong, J., Behavior of corrosion damaged circular reinforced concrete columns under cyclic loading. Construction and Building Materials, 29, pp. 548-556, 2012.

[3] Wang, X. H. \& Liang, F. Y., Performance of RC columns with partial length corrosion. Nuclear Engineering and Design, 238(12), pp. 3194-3202, 2008.

[4] Ou, Y. C., Fan, H. D. \& Nguyen, N. D., Long-term seismic performance of reinforced concrete bridges under steel reinforcement corrosion due to chloride attack. Earthquake Engineering \& Structural Dynamics, 42(14), pp. 2113-2127, 2013.

[5] Sæther, Irina \& Sand, Bjørnar. FEM simulations of reinforced concrete beams attacked by corrosion, 2010.

[6] Abaqus 6.10 Documentation, http://www.tu-chemnitz.de/projekt/abq hilfe/docs/v6.10/

[7] Bazant, Z. P. "Physical model for steel corrosion in concrete sea structures - application". Journal of the structural division 105.ASCE 14652 Proceeding, 1979.

[8] Liu, T. \& Weyers, R. W., Modeling the dynamic corrosion process in chloride contaminated concrete structures. Cement and Concrete Research, 28(3), pp. 365-379, 1998.

[9] Vu, K., Stewart, M. G. \& Mullard, J., Corrosion-induced cracking: experimental data and predictive models. ACI structural journal, 102(5), 2005. 
[10] Li, J., Gong, J. \& Wang, L., Seismic behaviour of corrosion-damaged reinforced concrete columns strengthened using combined carbon fiber-reinforced polymer and steel jacket. Construction and Building Materials, 23(7), pp. 2653-2663, 2009.

[11] Lee, H. S., Noguchi, T. \& Tomosawa, F., Evaluation of the bond properties between concrete and reinforcement as a function of the degree of reinforcement corrosion. Cement and Concrete research, 32(8), pp. 1313-1318, 2002.

[12] Comité euro-international du béton, CEB-FIP Model Code 1990: Design Code. No. 213-214. FIB-Féd. Int. du Béton, 1993.

[13] Xu S.H., Degradation model of Reinforced Concrete Structure and Durability Assessment, Doctoral dissertation, Xi'an University of Architecture and Technology, 2003. (In Chinese Language).

[14] Freeman, S. A., Nicoletti, J. P. \& Tyrell, J. V. Evaluations of existing buildings for seismic risk-A case study of Puget Sound Naval Shipyard, Bremerton, Washington. In Proceedings of the 1st US National Conference on Earthquake Engineering, pp. 113-122, 1975.

[15] Federal Emergency Management Agency (FEMA), National Institute of Building Sciences (NIBS), Earthquake loss estimation methodology: HAZUS 99, Washington, DC, USA, 1999. 